\title{
CONTABILIDADE EM ORGANIZAÇÕES DO TERCEIRO SETOR: A PRESTAÇÃO DE CONTAS DE UMA OSCIP EM RECIFE
}

https://dx.doi.org/10.48097/2674-8673.2022n6p05

Elizany Ivania de Santana ${ }^{1}$

Waldete Moura de Lima $^{2}$

Tarciana Borges Ferreira ${ }^{3}$

\section{RESUMO}

O presente trabalho apresenta o resultado de uma pesquisa realizada na empresa SoftexCentro de Excelência em Tecnologia de Software de Recife. O intuito é mostrar as práticas contábeis de uma empresa sem fins lucrativos de acordo com as Normas Brasileiras de Contabilidade. O nosso universo foi sobre as demonstrações contábeis prestadas por uma OSCIP conforme as Normas Brasileiras de Contabilidade. O tipo de pesquisa desenvolvida quanto à forma foi bibliográfica e de campo; quanto a finalidade: aplicada; quanto ao método de análise: propositiva; quanto a abordagem: qualitativa. $\mathrm{O}$ instrumento de pesquisa foi um questionário fechado, com perguntas e alternativas de múltipla escolha. O objeto de estudo desse artigo foi a Contabilidade de uma Organização de Sociedade - OSCIP.

Palavras-chave: Terceiro Setor. OSCIP. Prestação de Contas.

Data de submissão: 09/09/2021

Data de aprovação: $26 / 10 / 2021$

\begin{abstract}
The present work presents the result of a research carried out at the company Softex- Recife Center for Excellence in Software Technology. The purpose is to show the accounting practices of a non-profit company in accordance with the Brazilian Accounting Standards. Our universe was about the financial statements provided by an OSCIP in accordance with the Brazilian Accounting Standards. The type of research developed in terms of form was: bibliographic and field; as for the purpose: applied; regarding the method of analysis: propositional; as for the approach: qualitative. The research instrument was a closed questionnaire, with multiple choice questions and alternatives. The object of study of this article was the Accounting of an Organization of Society - OSCIP.
\end{abstract}

Keywords: Third Sector. OSCIP. Accountability.

\footnotetext{
${ }^{1}$ Concluinte do curso de Bacharelado em Ciências Contábeis da Faculdade Metropolitana da Grande Recife.

E-mail: elizanysantana@hotmail.com

${ }^{2}$ Concluinte do curso de Bacharelado em Ciências Contábeis da Faculdade Metropolitana da Grande Recife.

E-mail: waldetemoura@hotmail.com

${ }^{3}$ Docente orientadora do curso de Ciências Contábeis da Faculdade Metropolitana da Grande Recife.

E-mail: tarciana@metropolitana.edu.br
} 


\section{INTRODUÇÃO}

Terceiro setor é uma expressão criada para designar um campo da sociedade correspondente às ações sociais promovidas por instituições privadas de caráter não lucrativo, com atividades que envolvem a demanda pela reivindicação de determinadas causas ou ações de filantropia. Esse termo foi criado para diferenciar essas instituições da esfera governamental (o Primeiro Setor) e da esfera privada com fins lucrativos (o Segundo Setor ou mercado). As mais conhecidas instituições do Terceiro Setor são as ONGs (Organizações Não Governamentais), havendo também as fundações, entidades beneficentes, os fundos comunitários, as entidades sem fins lucrativos, associações de moradores, entre outras. Em vista legal (Código Civil), as ONGs são pessoas jurídicas, de direito privado, constituídas em forma de associações ou fundações e para garantir os direitos sociais básicos e combater a exclusão social. Estas entidades são mantidas por iniciativas privadas, doações e até mesmo repasses de verbas públicas.

Como qualquer projeto ou empresa, uma entidade do Terceiro Setor precisa ser economicamente sustentável para que tenha continuidade. É possível ainda produzir e comercializar produtos e serviços, porém a receita e o superávit alcançados deverão ser totalmente revertidos para a manutenção e melhoria da entidade. E mesmo não visando o lucro, é extremamente importante ter um acompanhamento contábil eficiente para ter melhores resultados em suas ações, principalmente na demonstração da aplicação dos recursos obtidos.

\section{REFERENCIAL TEÓRICO}

O referencial desse estudo tem o objetivo de apresentar a grande importância da contabilidade para o terceiro setor, pois, com o auxílio desta, é possível demonstrar para a sociedade o trabalho que realmente vem sendo desenvolvido por parte dessas instituições sem fins lucrativos.

\section{Conceito de Terceiro Setor}

De Acordo com o SINIBREF (2016) o terceiro setor é um grupo formado pelas associações e fundações de direito privado, sem fins lucrativos, que buscam, dentre suas finalidades, o alcance do bem estar social. Essas instituições apresentam, ao mesmo tempo, características intrínsecas ao setor estatal, quando administram recursos públicos e buscam fins sociais, e ao setor privado, devido a sua própria constituição e natureza jurídica. 
Antes de conceituar o terceiro setor é interessante conhecer os outros dois setores existentes. O Estado é considerado o primeiro setor, compreendendo todas as esferas governamentais e abrangendo as instituições federais, estaduais e municipais "[...]: isto é, as prefeituras municipais, os governos dos estados e o presidente da república [...]”. Já o segundo setor, também chamado de "mercado", é constituído por empresas privadas, que competem entre si e trabalham visando o próprio lucro, que é obtido por meio de atividades econômicas, podendo ser a comercialização tanto de produtos, quanto de serviços. (E-DOU, 2017).

Diante desse entendimento, se compreende que existe uma conexão entre o terceiro setor e os demais setores. Paes (1999) destaca que:

O terceiro setor é composto por organizações de natureza "privada" (sem o objetivo de lucro), dedicadas à consecução de objetos sociais ou públicos, embora não seja integrante do governo (Administração Estatal). Podemos assim conceituar o Terceiro Setor como o conjunto de organismos, organizações ou instituições dotadas de autonomia e administração própria que apresentam como função e objetivo principal atuar voluntariamente junto à sociedade civil visando ao seu aperfeiçoamento. (PAES, 1999, p. 46).

O Observatório do Terceiro Setor (2019) conceitua que, “[...] o terceiro setor é composto por organizações sem fins lucrativos e de interesse público, as chamadas organizações da sociedade civil (OSCs)". Paes (1999) ressalta que:

O terceiro setor tem um caráter estratégico da maior importância no âmbito de qualquer sociedade que se preocupe com o desenvolvimento social e a consolidação de valores democráticos, pluralistas, comprometidos com a solidariedade humana e o sentido de comunidade. (PAES, 1999, p. 47).

\section{Características do Terceiro Setor}

De acordo com o art. 44 do Novo Código Civil (Lei 10.406 de 2002), são pessoas jurídicas de direito privado: as associações; as sociedades; as fundações; as organizações religiosas; os partidos políticos. Conforme especifica Grazzioli et al (2015):

A associação é uma modalidade de agrupamento dotada de personalidade jurídica, sendo pessoa jurídica de direito privado voltado à realização de interesses dos seus associados ou de finalidade de interesse social, cuja existência legal surge com a inscrição do seu estatuto, em forma pública ou particular, no registro competente, desde que satisfeitos os requisitos legais (CC Art. 45), que ela tenha objetivo licito e esteja regularmente organizada. (GRAZZIOLI et al, 2015, p. 22).

Na visão de Menezes (2003), a associação é citada como uma pessoa jurídica de direito privado, criada com base na união de pessoas, em torno de uma finalidade não lucrativa. Segundo Grazzioli (2015):

[...] assim como as associações, as organizações religiosas são pessoas jurídicas formadas por pessoas que se unem para a realização de atividades sem finalidade lucrativa, voltadas à religiosidade e à profissão de fé, muitas vezes realizando atividade para a coletividade. (GRAZZIOLI et al, 2015, p. 43). 
O novo Código Civil, no art. 981, declara que se constitui sociedade as pessoas que mutuamente compelem a colaborar com bens ou serviços, para o exercício de atividade econômica e a partilha, entre si, dos resultados.

A maioria das organizações do terceiro setor goza de imunidade ou isenção tributária, sendo necessário, para tanto, o atendimento a pré-requisitos previstos na Constituição Federal, no Código Tributário Nacional, e em leis específicas. Uma dessas exigências para a obtenção do benefício fiscal corresponde à manutenção da escrituração das receitas e despesas em livros revestidos de formalidades capazes de assegurar sua exatidão, o que significa aderência às normas contábeis, em especial à Interpretação Técnica Geral nº 2002 - Entidade sem Fins de Lucro, aprovada pela Resolução do Conselho Federal de Contabilidade nº 1.409/2012.

\section{Normas Brasileiras de Contabilidade Referentes ao Terceiro Setor}

A Norma Brasileira de Contabilidade - NBC T 10.19.1.3 tem por objetivo definir os procedimentos que avaliam e registram os elementos e as variações patrimoniais da estrutura das demonstrações contábeis e as informações detalhadas a serem divulgadas em notas explicativas da instituição sem fins lucrativos. (CONSELHO FEDERAL DE CONTABILIDADE, 2002). Segue abai xo as normas que regem essa categoria:

NBCT TG - Estrutura Conceitual para Elaboração e Apresentação das Demonstrações Contábeis (Resolução Conselho Federal de Contabilidade 1.374/11);

NBC TG 07 (R2) - Subvenção e Assistência Governamentais (Resolução CFC /17);

NBC TG 26 (R5) - Apresentação das Demonstrações Contábeis (Resolução CFC /17);

Princípios da Contabilidade (Resolução CFC 1.282/10);

ITG (Interpretação Técnica Geral) 2000 (R1) - Escrituração Contábil (Resolução $\mathrm{CFC} / 11)$;

ITG (Interpretação Técnica Geral) 2002 (R1) - Entidade sem finalidades de lucros (Resolução CFC 1.412/15).

\section{Qualificação da OSCIP}

De acordo com o artigo $3^{\circ}$ da Lei $n^{\circ} .9 .790 / 99$ que determina a qualificação instituída somente será dada às pessoas jurídicas de direito privado, sem fins lucrativos, cujos objetivos sociais tenham pelo menos uma das seguintes finalidades: 
I - promoção da assistência social; II- promoção da cultura, defesa e conservação do patrimônio histórico e artístico; III- promoção gratuita da educação, observando-se a forma complementar de participação das organizações de que trata esta Lei; IVpromoção gratuita da saúde, observando-se a forma complementar de participação das organizações de que trata esta Lei; V- promoção da segurança alimentar e nutricional; VI- defesa, preservação e conservação do meio ambiente e promoção do desenvolvimento sustentável; VII- promoção do voluntariado; VIII- promoção do desenvolvimento econômico e social e combate à pobreza; IX-experimentação, não lucrativa, de novos modelos socioprodutivos e de sistemas alternativos de produção, comércio, emprego e crédito; X- promoção de direitos estabelecidos, construção de novos direitos e assessoria jurídica gratuita de interesse suplementar; XI- promoção da ética, da paz, da cidadania, dos direitos humanos, da democracia e de outros valores universais; XII- estudos e pesquisas, desenvolvimento de tecnologias alternativas, produção e divulgação de informações e conhecimentos técnicos e científicos que digam respeito às atividades mencionadas neste artigo. XIII- estudos e pesquisas para o desenvolvimento, a disponibilização e a implementação de tecnologias voltadas à mobilidade de pessoas, por qualquer meio de transporte. (BRASIL, 1999).

Mediante o cumprimento do art. $5^{\circ}$ da Lei $n^{\circ} .9 .790 / 99$, a pessoa jurídica de direito privado sem fins lucrativos interessados em obter a qualificação de OSCIP, deverá requerer requerimento escrito ao Ministério Público, instruídos com os seguintes documentos: "Iestatuto registrado em cartório; II- ata de eleição de sua atual diretoria; III- balanço patrimonial de demonstração do resultado do exercício; IV- declaração de isenção de imposto de renda; V- inscrição no cadastro geral de contribuintes". (BRASIL, 1999). Segundo o Grazzioli, os principais benefícios da qualificação de OSCIP são:

A possibilidade de celebração do termo de parceria com o Poder Público para o recebimento de recursos; A possibilidade de o doador - pessoa jurídica - deduzir do cálculo do lucro real e da base de cálculo da Contribuição Social sobre o Lucro até o limite de $2 \%$ sobre o lucro operacional, o valor das doações efetuadas, conforme previsto no Art. 59, da Medida Provisória n ${ }^{\circ}$ 2.158-35, de 27/8/20014 e Art. 34 da Lei ${ }^{\circ} 10.637 / 2002$. (GRAZZIOLI et al, 2015, p. 77).

\section{Evidenciação de Receita e Despesa}

Segundo o Conselho Federal de Contabilidade, a Interpretação Técnica Geral (ITG2002) enfatiza que:

As receitas e as despesas devem ser reconhecidas, respeitando-se o regime contábil de competência. As doações e subvenções recebidas para custeio e investimentos devem ser reconhecidas no resultado observado o disposto na NBC TG 07 Subvenção e Assistência Governamentais. Os registros contábeis devem evidenciar as contas de receitas e despesas, com e sem gratuidade, superávit ou déficit, de forma segregada, identificáveis por tipo de atividade, tais como educação, saúde, assistência social e demais atividades. (CONSELHO FEDERAL DE CONTABILIDADE, 2002).

\footnotetext{
${ }^{4}$ Altera a legislação das Contribuições para a Seguridade Social - COFINS, para os Programas de integração Social e de Formação do Patrimônio do Servidor Público - PIS/PASEP e do Imposto sobre a Renda, e dá outras providências.
} 


\title{
Demonstrações Financeiras
}

As entidades sem fins lucrativos devem elaborar as demonstrações contábeis de acordo com a ITG 2002 - Entidade sem finalidade de lucro, as demonstrações exigidas são: Balanço Patrimonial, Demonstrações do Resultado do Período, Demonstrações das Mutações do Patrimônio Líquido, Demonstrações do Fluxo de Caixa e Notas Explicativas.

\begin{abstract}
No Balanço Patrimonial, a denominação da conta Capital deve ser substituída por Patrimônio Social, integrante do grupo Patrimônio líquido. No Balanço Patrimonial e nas Demonstrações do Resultado do Período, das Mutações do Patrimônio Líquido e dos Fluxos de Caixa, as palavras lucro ou prejuízo devem ser substituídas por superávit ou déficit do período. Na Demonstração do Resultado do Período, devem ser destacadas as informações de gratuidade concedidas e serviços voluntários obtidos, e divulgadas em notas explicativas por tipo de atividade. Na Demonstração dos Fluxos de Caixa, as doações devem ser classificadas nos fluxos das atividades operacionais. (CONSELHO FEDERAL DE CONTABILIDADE, 2002).
\end{abstract}

\section{Prestações de Contas das OSCIPS}

A prestação de contas implica em comprovar de forma correta a utilização dos recursos revertidos à Organização da Sociedade Civil de Interesse Público. Então, de acordo com o Decreto 3.100, de 30 de junho de 1999, a prestação de contas será formada com os seguintes relatórios:

Documento anual de execução de atividades;

Demonstração de resultados do exercício;

Balanço patrimonial;

Demonstração das origens e aplicações de recursos;

Demonstração das mutações do patrimônio social;

Notas explicativas;

Parecer e relatório de auditoria.

Se houver a efetivação do termo de parceria, é necessária a evidenciação, junto ao órgão parceiro, para mostrar o uso correto dos recursos públicos com os seguintes documentos, de acordo com o artigo 11 do Decreto 3.100/995:

I- Relatório anual de execução de atividades, contendo especificamente relatório sobre a execução do objeto do Termo de Parceria e comparativo entre as metas propostas e os resultados alcançados; II- Demonstrativo integral da receita e despesa realizadas na execução; III- Extrato da execução física e financeira; IV Demonstração de resultado do exercício; V-Balanço patrimonial; VI- Demonstração das origens e aplicações de recursos; VII- Demonstração das mutações do patrimônio social; VIII- Notas explicativas das demonstrações contábeis; IXParecer e relatório de auditoria. (BRASIL, 1999).

\footnotetext{
${ }^{5}$ Decreto $n^{\circ} 3100$, de 30 de junho de 1999 - regulamenta a lei n 9.790, de 23 de março de 1999, que dispõe sobre a qualificação de pessoas jurídicas de direito privado, sem fins lucrativos, como Organização da Sociedade Civil de Interesse Público, institui e disciplina o Termo de Parceria, e dá outras providências.
} 
A prestação de contas da entidade deve ser feita por um contador registrado no Conselho Regional de Contabilidade, observando as Normas Brasileiras de Contabilidade e os princípios fundamentais da contabilidade.

\section{METODOLOGIA}

O objeto de estudo desse artigo foi a contabilidade de uma Organização de Sociedade Civil de Interesse Público - OSCIP. Cujo objetivo geral foi identificar quais os procedimentos contábeis utilizados em uma organização do terceiro setor, formando assim os seguintes objetivos específicos: caracterizar as entidades do terceiro setor, apresentar alguns aspectos legais das entidades do terceiro setor e identificar os procedimentos contábeis utilizados na OSCIP.

O campo investigativo da pesquisa foi realizado na empresa Softex, localizada na cidade do Recife. O estudo foi sobre as demonstrações contábeis prestadas por uma OSCIP, conforme as Normas Brasileiras de Contabilidade. O tipo de pesquisa desenvolvida quanto à forma foi bibliográfica e de campo, com finalidade aplicada, método de análise propositiva, e de abordagem qualitativa. O instrumento de pesquisa foi um questionário fechado com perguntas e alternativas de múltipla escolha.

O Centro de Excelência em Tecnologia de Software do Recife - Softex Recife, qualificada como Organização da Sociedade Civil de Interesse Público - OSCIP, nos termos da Lei ${ }^{\circ}$ 9.970, de 23 de Março de 1999, caracteriza-se como uma instituição de educação, ensino e pesquisa de apoio ao desenvolvimento organizacional, institucional, técnico e econômico, tendo por finalidade conceber, desenvolver e executar atividades ligadas à pesquisa, extensão e inovação no campo da tecnologia da informação, tecnologia social e gestão, objetivando a promoção da sociedade, modernização e competitividade no Estado de Pernambuco, na Região Nordeste e no país.

\section{Desenvolvimento da Pesquisa de Campo}

O desenvolvimento da pesquisa de campo foi realizado na cidade de Recife, na empresa Softex - Centro de Excelência em Tecnologia de Software de Recife, que é uma Organização da Sociedade Civil de Interesse Público - OSCIP. O intuito da pesquisa foi mostrar as práticas contábeis de uma empresa sem fins lucrativos de acordo com as Normas Brasileiras de Contabilidade. 


\section{A Empresa}

A Softex Recife é uma associação de empresas de Tecnologia da Informação de Comunicação (TIC), sem fins lucrativos, criada em 8 de novembro de 1994. Foi o sexto núcleo criado no país. Em 2006 foi reconhecida como OSCIP - Organização da Sociedade Civil de Interesse Público nos níveis municipal, estadual e federal, com registro junto ao CATI - Conselho de Atividades de Tecnologia da Informação do Ministério da Ciência e Tecnologia. A missão da empresa é incrementar o sistema de negócios de TIC em Pernambuco, promovendo a integração, capacitação e certificação empresarial apoiando a inserção competitiva das empresas no mercado para aumentar os seus resultados.

A entidade ultrapassou a marca de 200 empresas associadas. A mesma está sediada no Bairro do Recife, onde administra um prédio próprio com 5 mil metros quadrados de área geral e 3.880 metros quadrados de área locável. Além das salas empresarias, conta com um centro de convenções no térreo, onde funciona um auditório para 50 pessoas, salas de reuniões e treinamentos, espaço para a realização de coffebreak, refeitório coletivo, um telhado verde para eventos e o Mangue Space, um coworking funcional e acessível.

\section{Instrumento para Coleta de Dados}

A entrevista foi realizada com o Coordenador Geral Eduardo Antônio Paiva de Almeida, que atua na empresa desde 2001. O mesmo informou que para um melhor acompanhamento as informações contábeis são preparadas mensalmente. Os relatórios são utilizados para prestar contas aos financiadores e para controle das operações. As demonstrações contábeis foram elaboradas de acordo com as práticas contábeis adotadas no Brasil, com base nas disposições contidas na ITG 2002 - Entidades sem finalidades de lucros, aprovada pela Resolução CFC n 1.409 de 21 de setembro de 2012, pelo comunicado Técnico CTG 2000, aprovado pela Resolução CFPC n 1.159 de 13 de fevereiro de 2009 e pela ITG 1000 - Modelo Contábil para Microempresa e Empresa de Pequeno Porte.

\section{Registros das Receitas}

As receitas e despesas são controladas através de um sistema ERP chamado PIRAMIDE. Além desse sistema se faz uso também de um acompanhamento do Fluxo de Caixa, por meio de uma planilha eletrônica. A contabilização das receitas e despesas de projetos terceiros são registradas nas contas do passivo, respeitando-se o regime de competência. 
Tabela 1 - Receita de atividades

\begin{tabular}{lcc}
\hline RECEITAS & 2019 & 2018 \\
\hline DOAÇÃO & 3.766 .799 & $\mathbf{3 . 0 9 0 . 6 8 9}$ \\
CONTRATOS/ PATROCÍNIOS & $\mathbf{1 . 6 7 7 . 3 5 4}$ & $\mathbf{1 . 9 9 3 . 7 1 8}$ \\
CONSULTORIA & $\mathbf{3 2 1 . 4 0 7}$ & $\mathbf{5 2 7 . 7 5 9}$ \\
ASSOCIADOS & $\mathbf{2 5 4 . 2 8 6}$ & $\mathbf{2 0 2 . 2 0 0}$ \\
TAXA DE ADMINISTRAÇÃO & $\mathbf{2 6 1 . 6 8 6}$ & $\mathbf{4 3 . 5 2 1}$ \\
GESTÃO DE PROJETOS & $\mathbf{3 5 6 . 2 1 3}$ & $\mathbf{2 9 8 . 5 8 9}$ \\
CURSOS & $\mathbf{1 . 8 0 0}$ & - \\
RECEITA DE LOCAÇÃO & - & - \\
ALUGUEL & $\mathbf{1 . 7 8 2 . 8 6 9}$ & $\mathbf{1 . 6 6 1 . 5 5 5}$ \\
CONDOMÍNIO & $\mathbf{6 7 2 . 3 5 9}$ & $\mathbf{7 1 6 . 8 6 5}$ \\
OUTRAS RECEITAS & $\mathbf{1 1 . 9 4 9}$ & - \\
\hline
\end{tabular}

Fonte: Softex 2019

\section{Registros das Despesas}

A tabela 1 mostra quais as origens dos valores que foram adquiridos para a manutenção da empresa e desenvolvimento dos projetos. Já na tabela 2 é esclarecido onde foram aplicadas as receitas obtidas. Essas tabelas estão relacionadas às informações que estão transcritas na demonstração do resultado. Dessa maneira a empresa revela transparência na apresentação de seus relatórios.

Tabela 2 - Custo dos Serviços Prestados e Despesas Gerais e Administrativas

\begin{tabular}{lcc}
\hline CUSTOS SERVIÇOS & 2019 & 2018 \\
\hline BOLSAS & 3.952 .701 & 3.039 .747 \\
DEPRECIAÇÃO & 320.253 & 317.725 \\
OUTROS CUSTOS & 130.219 & 101.245 \\
& & \\
DESPESAS & 2019 & 2018 \\
CARTÓRIOS & 3.886 & $\mathbf{5 . 0 7 7}$ \\
DESPESAS DIVERSAS & $\mathbf{2 1 9 . 3 1 4}$ & $\mathbf{9 2 9 . 6 5 2}$ \\
COMERCIAL & $\mathbf{2 3 2 . 1 5 7}$ & $\mathbf{1 6 5 . 6 1 8}$ \\
VIAGENS & $\mathbf{3 4 . 6 4 1}$ & $\mathbf{2 7 . 7 0 0}$ \\
MATERIAIS & $\mathbf{9 5 . 3 1 4}$ & $\mathbf{7 8 . 9 0 3}$ \\
IMÓVEIS & 487.125 & $\mathbf{4 8 9 . 8 0 3}$ \\
PRESTAÇÃO DE SERVIÇOS & $\mathbf{2 . 1 4 0 . 8 3 9}$ & $\mathbf{2 . 5 2 8 . 7 4 9}$ \\
OUTROS IMPOSTOS E TAXAS & 150 & $\mathbf{5 3 . 8 7 5}$ \\
\hline
\end{tabular}




\begin{tabular}{ccc}
\hline TOTAL & 3.213 .426 & 4.279 .376 \\
\hline & Fonte: Softex 2019
\end{tabular}

\section{Prestação de Contas}

Os relatórios utilizados pela entidade são: o Balanço Patrimonial, a Demonstração do Resultado do Exercício, a Demonstração do Fluxo de Caixa, a Demonstração das Mutações do Patrimônio Líquido e Notas Explicativas. A prestação de contas se faz a partir das informações constantes no ERP atribuídas no projeto. As demonstrações foram apresentadas em forma comparativa, conforme a NBC TG 26 (R5). Cada demonstração e suas notas explicativas estão identificadas claramente. De acordo com a ITG 2002, no Balanço Patrimonial da Softex, a conta Capital foi substituída por Patrimônio Social e também as palavras lucro e prejuízo foram substituídas por superávit ou déficit do período. A escrituração observa os princípios da Contabilidade, como o da continuidade (intenção de continuar com a operação no futuro), oportunidade (mostram informações integras e tempestivas) e competência (registro do evento independente de recebimento ou pagamento).

Tabela 3 - Balanço Patrimonial

\begin{tabular}{|c|c|c|c|c|c|c|c|}
\hline $\begin{array}{l}\text { ATIVO } \\
\text { CIRCULANTE }\end{array}$ & $\begin{array}{l}\text { NOT } \\
\text { A }\end{array}$ & 2019 & 2018 & $\begin{array}{l}\text { PASSIVO } \\
\text { CIRCULANTE }\end{array}$ & NOTA & 2019 & 2018 \\
\hline $\begin{array}{l}\text { CAIXA E EQUIVALENTE } \\
\text { DE CAIXA }\end{array}$ & 4 & 1.320 .925 & 1.516 .194 & FORNECEDORES & & 207.982 & 120.686 \\
\hline CONTAS A RECEBER & 5 & 941.713 & 893.741 & $\begin{array}{l}\text { EMPRÉSTIMOS E } \\
\text { FINANCIAMENTOS }\end{array}$ & 7 & 198.240 & 861.085 \\
\hline $\begin{array}{l}\text { OUTRAS CONTAS A } \\
\text { RECEBER }\end{array}$ & - & 140.519 & 29.177 & $\begin{array}{l}\text { SALÁRIOS, } \\
\text { PROVISÕES E } \\
\text { ENCARGOS SOCIAIS }\end{array}$ & & 90.793 & 89.085 \\
\hline DESPESAS ANTECIPADAS & - & & 7.207 & $\begin{array}{l}\text { TRIBUTOS E } \\
\text { CONTRIBUIÇOES }\end{array}$ & & 29.639 & 32.999 \\
\hline $\begin{array}{l}\text { TOTAL DO ATIVO } \\
\text { CIRCULANTE }\end{array}$ & - & 2.402 .858 & 2.446 .319 & $\begin{array}{l}\text { PROJETOS RECURSOS } \\
\text { DE TERCEIROS }\end{array}$ & 8 & 752.418 & 995.428 \\
\hline & - & & & $\begin{array}{l}\text { TOTAL DO PASSIVO } \\
\text { CIRCULANTE }\end{array}$ & & 1.279 .073 & 2.099 .752 \\
\hline $\begin{array}{l}\text { NÃO CIRCULANTE } \\
\text { IMOBILIZADO }\end{array}$ & - & & & & & & \\
\hline NÃO CIRCULANTE & - & & & NÃO CIRCULANTE & & & \\
\hline IMOBILIZADO & 6 & 4.704 .044 & 4.950 .671 & $\begin{array}{l}\text { EMPRÉSTIMOS E } \\
\text { FINANCIAMENTOS }\end{array}$ & 7 & 70.544 & 127.187 \\
\hline $\begin{array}{l}\text { TOTAL DO ATIVO NÃO } \\
\text { CIRCULANTE }\end{array}$ & - & 4.704 .044 & 4.950 .671 & $\begin{array}{l}\text { TOTAL DO PASSIVO } \\
\text { NÃO CIRCULANTE }\end{array}$ & & 70.544 & 127.187 \\
\hline & & & & $\begin{array}{l}\text { PATRIMÔNIO } \\
\text { LÍQUIDO }\end{array}$ & & & \\
\hline
\end{tabular}




\begin{tabular}{|c|c|c|c|c|c|}
\hline & & & PATRIMÔNIO & 5.170 .051 & 5.182 .522 \\
\hline & & & \multicolumn{3}{|l|}{ SOCIAL } \\
\hline & & & SUPERÁVIT/ & \multirow[t]{3}{*}{587.234} & \multirow[t]{3}{*}{$(12.471)$} \\
\hline & & & DÉFICIT SOCIAL & & \\
\hline & & & ACUMULADO & & \\
\hline & & & TOTAL DO & \multirow[t]{3}{*}{5.757 .285} & \multirow[t]{3}{*}{5.170 .051} \\
\hline & & & PATRIMÔNIO & & \\
\hline & & & LÍQUIDO & & \\
\hline \multirow[t]{3}{*}{ TOTAL DO ATIVO } & 7.106 .902 & 7.396 .99 & TOTAL DO PASSIVO & \multirow[t]{3}{*}{7.106 .902} & \multirow[t]{3}{*}{7.396 .990} \\
\hline & & 0 & E PATRIMÔNIO & & \\
\hline & & & LÌQUIDO & & \\
\hline
\end{tabular}

Fonte: Softex 2019

Conforme Iudícibus, Marion e Faria (2009, p. 173) a demonstração do resultado confronta as receitas e despesas do período, gerando um resultado que pode ser positivo, negativo ou nulo. A tabela indica que a associação recebeu capital procedente de Convênio e Contratos de Prestação de Serviços estabelecidos com entidades governamentais. Posteriormente, na conta Custo dos Serviços Prestados, no resultado do exercício, estão incluídos os valores que foram pagos para as empresas contratadas e encarregadas pela execução dos serviços. No caso dos convênios, os valores são lançados como exigibilidades do passivo de longo prazo e não como receitas. Afora isso cada convênio é também objeto de uma auditoria especifica.

Tabela 4 - Demonstração do Resultado

\begin{tabular}{lccc}
\hline DEMONSTRATIVO & NOTA & 2019 & 2018 \\
\hline RECEITA LIQUIDA DE SERVICOS & $\mathbf{1 0}$ & 9.106 .721 & 8.534 .898 \\
CUSTO DOS SERVIÇOS PRESTADOS & $\mathbf{1 1}$ & $(4.403 .173)$ & $(3.458 .717)$ \\
SUPERÁVIT ANTES DAS DESPESAS E RESULTADO & & 4.703 .548 & 5.076 .717 \\
FINANCEIRO & & & \\
& & & $(3.213 .426)$ \\
DESPESAS GERAIS E ADMINISTRATIVAS & $\mathbf{1 2}$ & $(791.990)$ & $(669.377)$ \\
DESPESAS COM PESSOAL & & 698.132 & 127.428 \\
SUPERÁVIT DAS OPERAÇÕES ANTES DO & & & \\
RESULTADO FINANCEIRO E DOS IMPOSTOS & & 28.974 & 44.112 \\
RECEITAS FINANCEIRAS & & $(139.871)$ & $(187.175)$ \\
DESPESAS FINANCEIRAS & & 587.234 & $(15.365)$ \\
\hline SUPERÁVIT E DÉFICIT DO EXERCÍCIO & & & \\
\hline
\end{tabular}

Fonte: Softex 2019

Tabela 5 - Demonstração Das Mutações Do Patrimônio Líquido

NOTAS PATRIMÔNIO SOCIAL SUPERÁVIT/ DÉFICIT




\begin{tabular}{|c|c|c|c|c|}
\hline $\begin{array}{l}\text { SALDOS EM } 31 \text { DE } \\
\text { DEZEMBRO DE } 2017\end{array}$ & & 4.536 .460 & 646.063 & 5.182 .522 \\
\hline $\begin{array}{l}\text { AJUSTES DE } \\
\text { EXERCÍCIOS } \\
\text { ANTERIORES }\end{array}$ & 13 & & 3.164 & 3.164 \\
\hline $\begin{array}{l}\text { DÉFICIT DO } \\
\text { EXERCÍCIO }\end{array}$ & & & $(15.635)$ & (15.635) \\
\hline $\begin{array}{l}\text { ABSORÇÃO DE } \\
\text { SUPERÁVIT } \\
\text { ACUMULADO }\end{array}$ & & 646.063 & (646.063) & \\
\hline $\begin{array}{l}\text { SALDOS EM } 31 \text { DE } \\
\text { DEZEMBRO DE } 2018\end{array}$ & & 5.182 .522 & $(12.741)$ & 5.170 .051 \\
\hline $\begin{array}{l}\text { SUPERÁVIT DO } \\
\text { EXERCÍCIO }\end{array}$ & & & 587.234 & 587.234 \\
\hline $\begin{array}{l}\text { ABSORÇÃO DE } \\
\text { SUPERÁVIT } \\
\text { ACUMULADO }\end{array}$ & & (12.741) & 12.741 & \\
\hline $\begin{array}{l}\text { SALDOS EM } 31 \text { DE } \\
\text { DEZEMBRO DE } 2019\end{array}$ & & 5.170 .051 & 587.234 & 5.757 .285 \\
\hline
\end{tabular}

Fonte: Softex 2019

Tabela 6 - Demonstração do Fluxo de Caixa

\begin{tabular}{|c|c|c|}
\hline & 2019 & 2018 \\
\hline \multicolumn{3}{|l|}{ FLUXO DE CAIXA DAS ATIVIDADES OPERACIONAIS } \\
\hline DÉFICIT/ SUPERÁVIT DO EXERCÍCIO & 587.234 & $(15.635)$ \\
\hline \multicolumn{3}{|l|}{ AJUSTES PARA RECONCILIAR O SUPERÁVIT AO FLUXO DE CAIXA } \\
\hline \multicolumn{3}{|l|}{ DAS ATIVIDADES OPERCIONAIS: } \\
\hline \multirow[t]{2}{*}{ DEPRECIAÇÕES } & 320.253 & 317.725 \\
\hline & 907.487 & 302.090 \\
\hline \multicolumn{3}{|l|}{ VARIAÇÃO DE ATIVOS E PASSIVOS: } \\
\hline CONTAS A RECEBER DE CLIENTES & $(47.673)$ & $(384.601)$ \\
\hline IMPOSTOS A RECUPERAR & & - \\
\hline ADIANTAMENTOS & $(111.342)$ & 502.989 \\
\hline DESPESAS ANTECIPADAS & 7.207 & $(6.977)$ \\
\hline FORNECEDORES & 87.295 & $(4.436)$ \\
\hline OBRIGAÇÕES SOCIAIS E FISCAIS & $(2.120)$ & 39.307 \\
\hline PROJETOS DE TERCEIROS & $(243.010)$ & 862.428 \\
\hline CAIXA LÍQUIDO DAS ATIVIDADES OPERACIONAIS & 597.845 & 1.310 .800 \\
\hline FLUXO DE CAIXA DAS ATIVIDADES DE INVESTIMENTOS & $(73.626)$ & $(14.498)$ \\
\hline \multicolumn{3}{|l|}{ AUMENTO DE ATIVO IMOBILIZADO } \\
\hline CAIXA LÍQUIDO DAS ATIVIDADES DE INVESTIMENTOS & $(73.626)$ & $(14.498)$ \\
\hline FLUXO DE CAIXA DAS ATIVIDADES DE FINANCIAMENTO & $(719.488)$ & $(762.763)$ \\
\hline \multicolumn{3}{|l|}{ VARIAÇÃO NA CONTA DE EMPRÉSTIMOS } \\
\hline CAIXA LÍQUIDO DAS ATIVIDADES DE FINANCIAMENTO & $(719.488)$ & $(762.763)$ \\
\hline AUMENTO LÍQUIDO/ REDUÇÃO DE CAIXA E EQUIVALENTES DE & $(195.269)$ & 533.539 \\
\hline \multicolumn{3}{|l|}{ CAIXA } \\
\hline CAIXA E EQUIVALENTES DE CAIXA NO PERÍODO & 1.516 .194 & 982.655 \\
\hline CAIXA E EQUIVALENTES DE CAIXA NO FINAL DO PERÍODO & 1.320 .925 & 1.516 .194 \\
\hline
\end{tabular}

Fonte: Softex 2019 


\section{Notas Explicativas}

A resolução do $\mathrm{CFC} \mathrm{n}^{\circ}$ 838/00 estabelece que as entidades sem fins lucrativos podem utilizar os procedimentos das entidades sindicais e de classe, que dispõe que as notas explicativas devem incluir informações de natureza patrimonial, econômica, financeira, legal, física e social, tais como:

As principais atividades desenvolvidas pela entidade;

As práticas contábeis adotadas;

Os investimentos relevantes efetuados no período e os anteriormente existente;

A origem dos recursos relevantes;

Os detalhes dos financiamentos a longo prazo;

Os detalhes das contingências na data do encerramento do exercício, e dos prováveis efeitos futuros.

Conforme a norma a entidade detalha em suas notas explicativas todos esses processos, especificando cada ponto que precisa ser esclarecido, tais como:

Nota 1 - contexto operacional;

Nota 2 - base de elaboração e apresentação das demonstrações contábeis;

Nota 3 - resumo das principais práticas contábeis;

Nota 4 - caixa e equivalente de caixa;

Nota 5 - contas a receber;

Nota 6 - imobilizado;

Nota 7 - empréstimos e financiamentos;

Nota 8 - projetos recursos de terceiros;

Nota 9 - patrimônio social;

Nota 10 - receita liquida de serviços;

Nota 11 - custo dos serviços prestados;

Nota 12 - despesas gerais e administrativas;

Nota 13 - ajuste de exercícios anteriores.

\section{CONSIDERAÇÕES FINAIS}

O terceiro setor possui grande relevância na sociedade e por se tratar de organizações sem finalidade lucrativa existem algumas particularidades nas aplicações das práticas contábeis. Por isso é importante que o contador seja perspicaz no que se refere aos procedimentos aplicados nessas entidades. Nos últimos anos as entidades do terceiro setor 
vêm aumentando sua atuação na economia e a contabilidade se torna imprescindível para a sobrevivência destas instituições que têm a responsabilidade legal de ser transparente.

Os dados colhidos através da entrevista com o coordenador responsável mostrou que as informações contábeis da Sofitex foram apresentadas de acordo com as Normas Brasileiras de Contabilidade. A maneira coerente revela os esclarecimentos necessários para os associados e entidades governamentais. De forma isolada, os dados informados no balanço patrimonial são um pouco complexos, porém os elementos apresentados em seus relatórios auxiliares que são: a demonstração do resultado, a demonstração do fluxo de caixa, a demonstração das mutações do patrimônio líquido, bem como o controle das receitas e despesas e as notas explicativas, deixa a informação evidenciada de forma clara aos seus usuários.

Conclui-se que a Sofitex é uma entidade sólida que observa os princípios fundamentais da contabilidade e das Normas Brasileiras de Contabilidade, de maneira a promover aos seus financiadores a correta interpretação da sua condição patrimonial e financeira. E ao demonstrar as informações de forma compreensível, a entidade conseguirá maior fidedignidade e clareza de suas atividades. Afinal, uma empresa que utiliza subsídios públicos tem a obrigatoriedade de ser transparente e responsável na forma como utiliza os recursos que lhe foram confiados.

\section{REFERÊNCIAS}

BRASIL. Código civil - Lei $\mathbf{n}^{\circ} \mathbf{1 0 . 4 0 6}$ de janeiro de 2002. Disponível em: https://www.jusbrasil.com.br/topicos/10727903/artigo-44-da-lei-n-10406-de-10-de-janeirode-2002. Acesso em: 08 dez. 2020.

Decreto $\mathbf{n}^{\circ}$ 3100, de 30 de junho de 1999. Disponível em: http://www.planalto.gov.br/ccivil_03/decreto/d3100.htm. Acesso em: 22 de set. 2020.

Lei n 9.790, de março de 1999. Disponível em: http://www.planalto gov.br/ccivil_03/leis/19790.htm. Acesso em: 12 set. 2020.

Disponível

Resolução CFC. NBC T 10.8 - Entidades sindicais e associações de classe. https://www.lefisc.com.br/paginasExclusivas/terceiroSetor/conteudo/resolucoesCFC/resoluca oCFC838_99.htm. Acesso em: 12 out. 2020.

CONSELHO FEDERAL DE CONTABILIDADE. ITG (2002) - Entidade sem finalidade de lucros. Disponível em: https://www1.cfc.org.br/sisweb/SRE/docs/ITG2002(R1).pdf. Acesso em: 20 nov. 2020. 
E-DOU. Disponível em: https://e-dou.com.br/2017/06/primeiro-segundo-e-terceiro-setor/. Acesso em: 03 ago. 2020.

GRAZZIOLLI, Airton et al. Manual de procedimentos do terceiro setor: aspectos de gestão e de contabilidade para entidades de interesse social. Brasília: CFC: FBC: Profis, 2015 .

IUDÍCIBUS, Sérgio de; MARION, José Carlos; FARIA, Ana Cristina de. Introdução à Teoria da Contabilidade. 5. ed. São Paulo: Atlas. 2009.

MENEZES, Leila Soraya (Cor.). Manual de administração jurídica, contábil e financeira para organizações não-governamentais. São Paulo: Peirópolis, 2003.

OBSERVATÓRIO DO TERCEIRO SETOR. Disponível em: https://observatorio3setor.org.br/o-que-e/. Acesso em: 02 nov. 2020.

PAES, José Eduardo Sabo. Fundações e entidades de interesse social. Brasília: Brasília Jurídica, 1999.

SINIBREF - Sindicato Interestadual das Instituições Beneficentes, Religiosas e Filantrópicas dos Estados. Disponível em: http://www.sinibref-interestadual.org.br/a-importancia-dacontabilidade-para-as-organizacoes-do-terceiro-bilidade $\% 20 \mathrm{~h} \% \mathrm{C} 3 \% \mathrm{~A} 1 \% 20$ algum m\%2C\%20os. Acesso em: 10 set. 2020. 